\title{
Filosofar com o cinema
}

Daniel Donato Piasecki33

Resumo: Uma das dificuldades encontradas no ensino da Filosofia, está na visualização do aluno do tema/problema abordado com o mundo, ou de outra maneira, a dificuldade se encontra na aproximação que o professor deve realizar entre o tema/problema e o mundo do aluno. Frente a esta dificuldade, a pesquisa pretende fundamentar a utilização do cinema para o processo de ensinoaprendizagem nas aulas de Filosofia no ensino médio, tendo como ponto de partida uma obra cinematográfica, não excluindo a importância da utilização de outros recursos, como o texto filosófico. Os objetivos da pesquisa são contribuir para a metodologia do ensino de Filosofia no ensino médio e relatar experiência no âmbito do PIBID Filosofia da UNICENTRO com a ferramenta investigada e proposta.

Palavras-chave: cinema; ensino; filosofia.

\section{Filosofar con el cine}

Resumen: Una de las dificultades encontradas en la enseñanza de la filosofía está en la visualización del alumno sobre el tema/problema abordado con el mundo, o de otro modo, la dificultad radica en la aproximación que el maestro debe llevar a cabo entre el tema/problema y el mundo del estudiante. Ante esta dificultad, la investigación pretende apoyar el uso del cine en el proceso de enseñanza y aprendizaje en las clases de filosofía en la educación secundaria, tomando como punto de partida la obra cinematográfica, sin excluir la importancia del uso de otras características, tales como el texto filosófico. Los objetivos de la investigación son contribuir a la metodología de la enseñanza de la Filosofía en la enseñanza secundaria y relatar la experiencia en el ámbito del PIBID Filosofía de UNICENTRO con la herramienta investigada y propuesta.

Palabras-clave: cine; enseñanza; filosofía.

\section{Introdução}

O recente retorno da Filosofia como disciplina nas escolas brasileiras, de maneira obrigatória, reacendeu a problematização sobre o seu ensino no nível de educação médio, ocorrendo que o ensino de Filosofia se torna um

33Professor da Rede Estadual de Ensino do Estado do Paraná e Supervisor do subprojeto PIBID Filosofia (UNICENTRO). E-mail: dadosecki@seed.pr.gov.br

Revista Digital de Ensino de Filosofia - Santa Maria - vol.2., n.2 - jul./dez. 2016. 
problema da própria Filosofia.

Nessa perspectiva, as páginas que se seguem inserem-se nessa problematização do ensinar filosófico, abordando algumas dificuldades encontradas no processo ensino-aprendizagem, para propor maneiras de superação e efetivação do fazer filosófico em salas de aula com diversas realidades. Porém, deve-se alertar ao leitor de que a reflexão efetuada não se esgota aqui, tampouco se pretende apresentar um receituário de como se deve proceder para a efetivação de um ensino de Filosofia.

Uma das dificuldades encontradas no ensino da Filosofia, está na visualização do aluno do tema/problema abordado com o mundo, ou de outra maneira, a dificuldade se encontra na aproximação que o professor deve realizar entre o tema/problema e o mundo do aluno. A utilização do cinema pode contribuir para o processo de ensino-aprendizagem nas aulas de Filosofia no ensino médio, tendo como ponto de partida uma obra cinematográfica, não excluindo a importância da utilização de outros recursos, como o texto filosófico. Dessa forma objetiva-se com esta pesquisa contribuir para a metodologia do ensino de Filosofia no ensino médio, compreendendo uma abordagem filosófica do cinema proposta pelo filósofo Júlio Cabrera (2006) e expondo uma experiência com a ferramenta investigada e proposta nos anos de 2014-2015 no âmbito do subprojeto Filosofia do PIBID da Unicentro em Guarapuava.

\section{Sobre o ensino de Filosofia}

Algumas instituições de ensino superior tem se preocupado com a problemática do ensino de Filosofia, algo recente, já que durante muito tempo não havia essa preocupação com o ensino de Filosofia em níveis que não fossem acadêmicos, como é o caso da inserção no evento da ANPOF ${ }^{34}$, um

\footnotetext{
${ }^{34}$ Associação Nacional de Pós-graduação em Filosofia, fundada em março de 1983 , congrega todos os cursos de mestrado e doutorado em Filosofia do Brasil, credenciados pela CAPES, e tem como um de seus principais objetivos estimular, em todos os níveis, a investigação filosófica no País. Incluiu no encontro de 2012, na cidade de Curitiba, a ANPOF-Ensino Médio, para debater o ensino de Filosofia no Revista Digital de Ensino de Filosofia - Santa Maria - vol.2., n.2 - jul./dez. 2016.
} 
evento paralelo intitulado de ANPOF Ensino Médio, que teve sua primeira edição em 2012 e a segunda em 2014, com avanços na área de ensino de Filosofia, que além das apresentações de experiências em sala de aula, levantaram a possibilidade de um mestrado profissional em ensino de Filosofia que deve ocorrer nos próximos anos.

Com o retorno da Filosofia aos bancos escolares no nível médio, surgiram algumas preocupações quanto ao que ensinar, como ensinar e que encaminhamentos deve o professor nesse nível de ensino tomar. Apesar de haver alguns documentos que orientem o ensino de Filosofia no âmbito federal, como já citados, muitos Estados brasileiros também produziram alguns documentos orientadores para a disciplina, como é o caso do Estado do Paraná, através das DCE's. Positivamente, há uma certa liberdade no tratamento de conteúdos e formas de se trabalhar, pois o professor tem algumas orientações sobre os principais conteúdos e pode fazer o recorte ou delimitação do conteúdo que verificar necessário. Aproveitando isso e a necessidade de fortalecer o espaço da introdução da Filosofia como disciplina, proponho tratar aqui de alguns aspectos referentes ao ensino de Filosofia, refletindo sobre um encaminhamento para que se faça Filosofia na escola, com os alunos.

Formar o cidadão é a justificativa de toda a educação e estando a Filosofia inserida neste contexto é indiscutível que ela deverá tentar contribuir para que isso ocorra. Se afirmarmos que a disciplina tem como objetivo o "pensar", desmereceremos outras atividades e disciplinas.

Mas o que se espera, creio que é que os alunos pensem filosoficamente, compreendendo os problemas e temas da Filosofia, dentro dos contextos que foram pensados e capaz então de produzir também filosoficamente. Porque toda disciplina que se encontra em qualquer nível educacional, se torna legítima para que o aluno a pratique, ou seja, se a Filosofia se encontra no ensino médio, é para que os alunos filosofem, tenham a experiência do filosofar.

O objetivo final de todo professor de Filosofia

Ensino Médio Brasileiro.

Revista Digital de Ensino de Filosofia - Santa Maria - vol.2., n.2 - jul./dez. 2016. 
deverá ser fazer de seus alunos, em alguma medida, filósofos. Em virtude disso, deverá tentar promover neles uma atitude filosófica, já que será ela que, eventualmente, dará lugar ao desejo de filosofar. Nesse marco, os textos filosóficos serão uma ferramenta central para o filosofar, mas não um fim em si mesmo. Compreender um texto é um passo no caminho da filosofia, e não o último. (CERLLETI, 2009, p. 81)

A proposta aqui apresentada concorda com a proposta do autor citado, afirmando que não há outro motivo senão que os alunos tenham contato com a Filosofia e conheçam sobre ela, sendo impossível ter contato com toda Filosofia existente. Mesmo com os direcionamentos dados pelos documentos orientadores da disciplina, os recortes dos temas e conteúdos serão produto da ação docente, fruto de toda sua trajetória e concepções de mundo, de educação e de Filosofia, ao selecionar partes do que compõe o saber filosófico para a sala de aula.

Mas existem várias definições de Filosofia, o que acaba determinando o encaminhamento que se dá a partir de uma determinada concepção de Filosofia. Qual é a concepção que orienta essa pesquisa? Penso que a definição proposta pelo filósofo francês Michel Foucault é um ponto de partida interessante:

\footnotetext{
Mas o que é filosofar hoje em dia - quero dizer, a atividade filosófica - senão o trabalho crítico do pensamento sobre o próprio pensamento? Se não consistir em tentar saber de que maneira e até onde seria possivel pensar diferentemente em vez de legitimar o que já se sabe? Existe sempre algo de irrisório no discurso filosófico quando ele quer, do exterior, fazer a lei para os outros, dizerIhes onde está a sua verdade e de que maneira encontrá-la, ou quando pretende demonstrar-se por positividade ingênua; mas é seu direito explorar o que pode ser mudado, no seu próprio pensamento, através do exercício de um saber que lhe é estranho [...] (FOUCAULT, 1984, p. 13)
}

A Filosofia que aqui se concebe é encarada como uma busca pela verdade, busca pela autenticidade no pensamento que visa ir além das aparências das coisas, questionando o que são e como são as coisas, que busca fazer a crítica de nossas crenças. Crenças não no sentido religioso, mas 
em tudo aquilo que tomamos como verdadeiro, que na maioria das vezes se dá de maneira acrítica, ou seja, tudo aquilo que reproduzimos como verdade antes mesmo de termos feito a análise da sua veracidade, que comumente recebemos de uma autoridade (pais, professores, instituições). A Filosofia como a entendemos é como o adolescente, é subversiva, pois ela não aceita tudo como pronto e acabado, ela necessita de análise do que está posto, antes mesmo de tomar como verdadeiro. A Filosofia aqui é entendida como uma forma de conhecimento que contribui para o entendimento do mundo e de si mesmo, possibilitando a construção de si e também do outro, capaz de contribuir para o movimento do indivíduo no mundo durante a sua existência. É a Filosofia como forma de vida, como constituinte das nossas ações, capacidade de fazer a análise de fazer a crítica, que quando adquirida, pode acompanhar nossos passos no mundo para que não se tome o discurso do outro como verdadeiro sem antes passar pelo crivo da razão.

A Filosofia que orienta essa pesquisa, portanto, encontra-se na perspectiva de inicialmente não tomar nada como definitivo, como verdade, sem investigar, encarando o presente como a possibilidade de ser algo diferente, que é construído na reflexão e ação a partir de nós mesmos. Problematizando nós mesmos, na busca por saber o que se fez de nós e investindo em alternativas do que podemos constituir a nós mesmos.

Mas para que isso se efetive, o educador deve ser o criador de instrumentos e estratégias para seus educandos, levando em conta as especificidades das realidades que tem contato, percebendo quais materiais e métodos se prestam a ser repetidos e quais não (ASPIS, 2004, p.31). A autora refere-se ao professor-filósofo como um artesão, que confecciona exercícios, seleciona textos, cria atividades e jogos. Ou seja, produzir a sua maneira de lecionar, construindo os recursos para o trabalho daquele conteúdo, que naquele momento compreende ser o melhor possível e que poderá dar conta do que pretende propor. Entende-se que se deve levar em conta a realidade que se encontra o professor, sua carga horária, seu acesso aos materiais que podem propiciar esse desenvolvimento artesanal das aulas, os condicionantes da sua formação e possibilidade de formação continuada.

Buscar conhecer cada vez mais a Filosofia e também procurar exercitar a Filosofia, além de ter sensibilidade de como conduzir as aulas, são pontos Revista Digital de Ensino de Filosofia - Santa Maria - vol.2., n.2 - jul./dez. 2016. 
que são necessários para o desenrolar daquilo que se espera, que os alunos possuam conhecimento filosófico ao terem experiências filosóficas.

Se considerarmos o ensino de filosofia como filosófico, o professor deverá ser um filósofo que cria e recria cotidianamente um conjunto de problemas filosóficos e suas tentativas de resposta, e isso ele não fará sozinho, mas com seus alunos. (CERLETTI, 2009, p. 83)

Além disso, talvez seja no colégio a única oportunidade que alguns alunos tenham a possibilidade de ter contato com a Filosofia, por isso35:

Um curso de filosofia no ensino médio ou nos cursos técnicos profissionalizantes se insere em um enorme quadro fragmentário de disciplinas dissímeis e desconectadas, colocado sob os olhos dos estudantes que o assimilam como podem. A responsabilidade do professor é conseguir que esse breve momento de contato com a filosofia seja significativo na vida escolar de um aluno. Se essas circunstâncias permitem, como viemos propondo, que os alunos cheguem a compartilhar o olhar sobre o mundo que os filósofos têm ou comecem a adquirir uma atitude filosófica, grande parte do esforço do professor filósofo estará justificado. (CERLETTI, 2009, p. 80)

Além disso, uma crítica que se pode fazer à disciplina de Filosofia, e também às demais disciplinas, é o caráter de isolamento em que elas se encontram. É possível afirmar que a Filosofia possui um potencial interdisciplinar ${ }^{36}$ muito grande, por transitar por temas semelhantes aos das

\footnotetext{
${ }^{35} \mathrm{~A}$ exemplo disso, pode-se observar o que ocorreu no Exame Nacional do Ensino Médio (ENEM) em 2015, principalmente na proposta da redação, levantando a discussão sobre a violência contra a mulher. É bem provável que seja apenas no espaço escolar que o aluno tenha a possibilidade de dialogar e refletir sobre esta ação da nossa sociedade, que está inserida em uma discussão ética. O não diálogo sobre este e outros temas, permite que indivíduos se expressem de forma a desconhecer sobre cultura, direitos humanos, ética e moral, além reproduzir o que receberam como verdade, sem ao menos verificar sua validade, sem refletir sobre suas práticas.

${ }^{36} \mathrm{~A}$ interdisciplinariedade pressupõem comunicabilidade entre as áreas do saber, e a Filosofia por não se restringir a um determinado tema apenas, é capaz de dialogar com as outras áreas, buscando em certa medida o conhecimento totalizante e não fragmentado. Dessa maneira, supera-se a mera reprodução da qual já tratamos e estimula o pensar para questões do presente, buscando soluções coerentes.

Revista Digital de Ensino de Filosofia - Santa Maria - vol.2., n.2 - jul./dez. 2016.
} 
demais disciplinas e, por isso, deveria utilizar-se desta característica para fazêla contribuir para o fortalecimento de uma visão ampliada sobre o mundo, capaz de ir ao encontro com outras disciplinas e possibilitando uma melhor compreensão dos problemas e soluções deles.

Dessa forma, o que se apresenta a seguir é uma alternativa de buscar esse ideal de Filosofia exposto acima, na tentativa de que se obtenha 0 Filosofar no espaço escolar.

\section{Filosofia e cinema - uma perspectiva}

Nessa perspectiva de Filosofia e da ação do professor como aquele que estimula e propicia momentos de filosofar em sala de aula, utilizando-se dos mais variados recursos, o cinema pode ser uma das alternativas. No entanto, o que será apresentado aqui, não é uma possibilidade de utilização do cinema como mera ilustração de teorias e pensamentos filosóficos ou de sensibilização, mas de que o próprio cinema é problematizador, é produtor de pensamentos, é ele mesmo filosófico.

Cabrera (2009. p. 9-10) afirma que os filmes constituem um conceito compreensivo do mundo, que ele conceitua como conceitos-imagem. Diferentemente da Filosofia que se utiliza da escrita e produz conceitos que são chamados por ele de conceitos-ideia, o cinema, visto filosoficamente, é um conceito visual que ele chama de conceitos-imagem (p. 20). Esses conceitos-imagem funcionam a partir de um contexto de uma experiência que é preciso ter para que se possa entender e utilizar, mas que não é meramente uma experiência estética determinando se o filme é bom ou ruim, mas a experiência que o próprio filme proporcione, por mais fantasioso que ele seja, ele propõem algo sobre o nosso mundo.

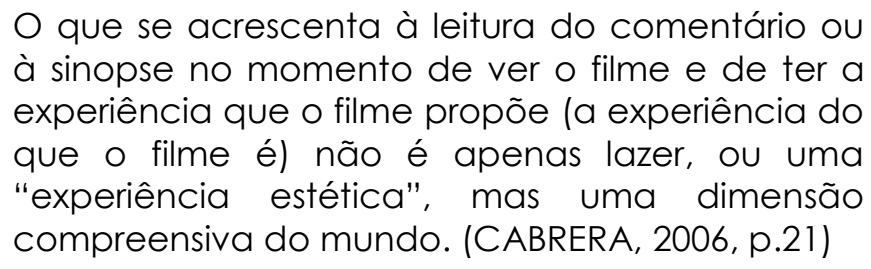

Não basta ver o filme para se fazer Filosofia com ele, é necessário interagir com os elementos lógicos que o constituem, compreender que há Revista Digital de Ensino de Filosofia - Santa Maria - vol.2., n.2 - jul./dez. 2016. 
uma ideia ou um conceito a ser transmitido pelas cenas em movimento (CABRERA, 2006, p. 22). Há que se tomar o cuidado de ao inserir a ferramenta filme para as aulas, de deixar claro para os educandos que não é um momento de lazer, de "matar aula", mas que há na obra algo a ser decifrado, compreendido, que faz parte do roteiro das aulas e faz parte do Filosofar. Pois a busca da verdade não pode estar apenas na tradição filosófica, ou seja, nos seus textos, mas ela também encontra-se em tudo que o ser humano faz, na sua cultura.

Assim, os conceitos-imagem serão identificados a partir de uma experiência que produza um impacto no indivíduos que esteja assistindo. Esse impacto é emocional e refere-se a algo do mundo que vivemos além de possuir

\begin{abstract}
um valor cognitivo, persuasivo e argumentativo através de seu componente emocional. Não estão interessados, assim, somente em passar uma informação objetiva nem em provocar uma pura explosão afetiva por ela mesma, mas em uma abordagem que chamo aqui de logopática, lógica e pática ao mesmo tempo. (CABRERA, 2006, p. 23)
\end{abstract}

Os conceitos-imagem portanto, referem-se a uma experiência logopática do cinema, em que o aspecto emocional (pática) e racional (logos) encontram-se para produzir no espectador uma experiência emocional e reflexiva. Pois não basta se apropriar de um problema filosófico, mas também é preciso vivenciá-lo, senti-lo, para que se possa compreendê-lo melhor. É o que normalmente se chama de sensibilização em algumas metodologias. Mas o que Cabrera propõem é mais do que isso, é a articulação entre o emocional e o racional para o fazer filosófico. Porém, cada um sente ou está predisposto diferentemente aos problemas filosóficos, assim como aconteceu aos filósofos, eles sentiram-se afetados por algumas questões ou temas, nem sempre pelas mesmas. Por isso, ao trabalhar com uma obra cinematográfica em sala de aula, não se pode ter a ilusão de que todos serão atingidos da mesma forma.

Ainda sobre ser mais do que uma sensibilização, Cabrera afirma: 
Os filósofos cinematográficos sustentam que algumas dimensões da realidade não podem simplesmente serem ditas e articuladas logicamente para que sejam entendidas, mas devem ser apresentadas sensivelmente, pela compreensão "logopática", racional e afetiva ao mesmo tempo. Essa apresentação sensível deve produzir algum tipo de impacto em quem estabelece um contato com ela. E por meio dessa apresentação sensível impactante, são alcançadas certas realidades que podem ser defendidas com pretensões de verdade universal, como experiências fundamentais ligadas à condição humana, com sentido cognitivo. (p. 21)

Os conceitos-imagem pretendem-se universais, mas dentro do campo das possibilidades e não da necessidade, pois o que ocorre no filme poderia acontecer com qualquer um. A sua linguagem, a do cinema, é metafórica mesmo quando parece ser literal, mas através de um distanciamento do real, do que nos é familiar o filme pode nos proporcionar ver o que não veríamos (CABRERA, 2006, p. 27). Além de que se não conseguirmos estabelecer uma relação logopática com a obra, não conseguiremos entender realmente o que o filme se pretende, independente do filme ser considerado uma obraprima do cinema ou uma obra insignificante, pois o que está em jogo não é a qualidade da produção, mas sim pelo impacto que as imagens causam emocionalmente, e também pelo seu conteúdo filosófico crítico e problematizador que é processado.

Segundo Cabrera (2006, p. 31-32) o impacto emocional que o cinema proporciona se dá por conta da técnica cinematográfica, que consiste principalmente em três aspectos. A pluriperspectiva, a manipulação de tempos e espaços e o corte cinematográfico.

A pluriperspectiva é a capacidade de saltar da primeira pessoa para a terceira, muitas vezes proporcionando ao espectador ter a visão do próprio ator, entrando em cena literalmente. Isso proporciona a quem assiste uma maneira de estar no filme, de visualizar o que o próprio personagem vê.

A manipulação de tempos e espaços, ou seja, de avançar ou retroceder na história, de inserir lembranças, como uma espécie de sonho, que as cenas se intercalam, criam o suspense, a não compreensão imediata dos acontecimentos, oportuniza a surpresa por conta de nem tudo ter sido 
revelado temporalmente.

E por terceiro, o corte cinematográfico, que é a maneira particular de ligar uma imagem à outra, propondo uma sequência específica. É como a sequência das frases de um escrito, que deve ser ajustado para a compreensão, para o ritmo da obra, para que ela chegue ao que se pretende.

Essas três técnicas são essenciais para o impacto emocional que a obra pode produzir e a partir dela a reflexão, a problematização filosófica, "Sem estes elementos, não existe conceito-imagem cinematográfico." (CABRERA, 2006, p. 32)

É característica do cinema e julgo importante para o ato de filosofar em sala de aula, que ele não pode mostrar sem problematizar, desestruturar, ou seja, o cinema desestabiliza, ele nos tira do lugar-comum e parece que a Filosofia também é isso, um pensamento que visa olhar de maneira diferente para compreender. E na sala de aula a problematização, a desestabilização daquilo que se tem como verdade, como certo, deve ocorrer. "O cinema é mais pagão do que a filosofia (não foi à toa que a primeira sessão de cinema ocorreu, segundo parece, na caverna de Platão). O cinema nunca confirma nada. Volta a abrir o que parecia aceito e estabilizado (CABRERA, 2006, p. 34)". Assim como a Filosofia, o cinema também é subversivo, são características semelhantes, que lhes aproximam.

Porém, o próprio autor alerta para o perigo da emoção, pois qualquer ideia, até mesmo as falsas, podem ser aceitas pela retórica da emoção. Dessa forma, a mediação emocional que o filme provoca, tem a ver com a apresentação da ideia filosófica e não com sua aceitação impositiva. A emoção é para entender e não para aceitar (CABRERA, p. 40). Dessa forma, a imagem não é a verdade, mas uma possibilidade, que nos apresenta algo o qual talvez não havíamos pensado, percebido. Assim como a leitura de um texto filosófico em um primeiro momento nos emociona e pensamos aquilo como uma verdade, o que pode ocorrer depois é realizar a crítica sobre aquilo, como deve ocorrer com o cinema.

Algo que os leitores podem estar se perguntando, é onde se encontram os conceitos-imagem dos filmes. A resposta a essa dúvida vai no sentido contrário a algumas recomendações que já se ouviu sobre trabalhar com Revista Digital de Ensino de Filosofia - Santa Maria - vol.2., n.2 - jul./dez. 2016. 
filmes em sala de aula. Pois os conceitos-imagen necessitam de tempo cinematográfico para que sejam desenvolvidos (CABRERA, 2006, p. 24). Pois como o que se espera é uma experiência, o desenrolar da trama, os elementos que compõem cada quadro, são importantes para a sua compreensão e utilizar apenas uma cena pontual, descontextualiza a obra. Por isso, defendo que a obra toda deve ser vista. Entendendo das dificuldades que são encontradas no ambiente escolar, como aulas não germinadas, duração do filme maior que o tempo das aulas.

Mas é possível organizar-se e trabalhar em conjunto com outros professores, para que o filme seja passado por completo e até mesmo utilizado na outra disciplina. Podendo ainda trabalhar com curtas ou selecionando filmes de menor duração. Tudo terá a ver com o que o professor-filósofo propõem. Ou, como apontaremos na próxima seção, uma alternativa de se utilizar os filmes.

\section{Pibid Filosofia}

Apresentam-se aqui o relato de uma experiência desenvolvida no âmbito do subprojeto Filosofia, do Programa Institucional de Bolsas de Iniciação a Docência - PIBID, da Universidade Estadual do Centro-Oeste do Paraná - Unicentro, Guarapuava.

O PIBID tem contribuído para a preparação de futuros professores, que foi criado em 2007 pelo Ministério da Educação e implementado pela CAPES (Comissão de Aperfeiçoamento de Pessoal do Nível Superior). É uma iniciativa para o aperfeiçoamento e a valorização da formação de professores para a educação básica, concedendo bolsas a alunos de licenciatura participantes de projetos de iniciação à docência desenvolvidos por Instituições de Educação Superior (IES), em parceria com escolas de educação básica da rede pública de ensino na qual os projetos são desenvolvidos. Os projetos devem promover a inserção dos estudantes no contexto das escolas públicas desde o início da sua formação acadêmica para que desenvolvam atividades didático-pedagógicas sob orientação de um docente da licenciatura e de um professor da escola.

Entre os principais objetivos do programa, destacam-se o incentivo à Revista Digital de Ensino de Filosofia - Santa Maria - vol.2., n.2 - jul./dez. 2016. 
formação de docentes em nível superior para a educação básica e elevar a qualidade da formação inicial de professores nos cursos de licenciatura, promovendo a integração entre educação superior e educação básica, através da sua inserção na realidade escolar, promovendo uma troca entre o professor da escola pública, o acadêmico e o professor da universidade.

Tenho a oportunidade de participar do programa como um dos supervisores dos acadêmicos, desde 2014. Várias são as atividades desenvolvidas no programa, mas a que será destacada, como já afirmado acima, é o da relação entre o cinema e a Filosofia. Como já apontado, trabalhar com o filme em sala de aula pode conter alguns problemas como a falta de tempo para iniciar e terminar o filme no mesmo dia.

Frente a esse problema, o PIBID Filosofia promoveu mês a mês sessões de cinema, em que os dois subprojetos que se encontravam em escolas diferentes, participavam juntas. As sessões eram realizadas no cinema da UNICENTRO, em contra turno. Todas elas não eram obrigatórias, dando liberdade de escolha aos alunos para que escolhessem participar ou não. Durante as sessões uma média de 30 pessoas se faziam presentes, mas alguns não eram alunos do ensino médio. Participavam também acadêmicos sem vínculo com o PIBID.

A organização da sessão do cinema passava pela escolha do filme, pela produção de um material de apoio, que consistia na elaboração de um texto a partir de um tema ou filósofo, que contribuísse para a discussão ao final do filme. Ao término do filme, os pibidianos iniciavam uma análise do filme, deixando aberto a palavra para quem quisesse participar, desenrolando-se assim um diálogo sobre o filme, com o levantamento de questões, problematizações e na busca do fazer filosófico.

O que se pode observar é que a partir da obra cinematográfica, o que Cabrera (2006) propõem, se deu de maneira variada, com obras que proporcionaram uma experiência logopática mais abrangente no público e outras não. Principalmente quando se tratou de inserir estilos de filmes que não eram habituais dos espectadores, como documentários e filmes que não contém o padrão "hollywoodianos".

Ainda assim, o leitor pode estar questionando-se e pensando que a proposta é inviável, já que na sua realidade provavelmente não há um Revista Digital de Ensino de Filosofia - Santa Maria - vol.2., n.2 - jul./dez. 2016. 
cinema próximo, tão pouco seria possível deslocar-se da sua escola com os alunos para uma sala de cinema, ou que seria impossível pensar em uma atividade que não fosse no turno dos educandos, ou ainda, que as dificuldades apresentadas sobre o tempo permanecem.

Mas uma alternativa cabível, possa ser o trabalho interdisciplinar. Dialogar com colegas de outras áreas e promover na escola, no turno em que os educandos se encontram, mensalmente, uma sessão de cinema, com tempo para assistir a obra cinematográfica e realizar o diálogo sobre ela. Podendo ser levada à frente a discussão ao longo dos dias nas suas respectivas disciplinas, focando o que é essencial para cada uma delas. Dessa maneira, seria possível realizar uma experiência diferenciada na escola, dentro das possibilidades da mesma.

\section{Conclusão}

O que foi exposto aqui, é uma concepção de Filosofia e busca de alternativa metodológica para o seu ensino. Ela não deve ser encarada como um receituário e nem ser vista como a alternativa salvadora para as suas aulas. Pois é certo que se ela for utilizada exaustivamente, em algum momento ela deixará de surtir efeito, por isso se propõem que seja utilizada com parcimônia.

Além disso, a teorização do uso do cinema para o fazer filosófico, proposto por Cabrera, pode contribuir para a defesa e a justificativa perante os colegas de profissão e aos educandos, de que não se trata de um momento meramente de diversão, de lazer, mas de uma experiência emocional e reflexiva a partir da arte, de mais um elemento da cultura. Isso contribuirá em certa medida para que os envolvidos não vejam o cinema passivamente, mas que ali também se encontra a Filosofia, que permeia de certa maneira tudo o que nos rodeia.

Finalizando, o que se espera nesse curto espaço de diálogo, é que a proposta seja experienciada e ajustada a cada realidade, criando-se alternativas metodológicas para $o$ ensino de Filosofia, desde que a experiência do filosofar esteja presente. 


\section{Referências}

ASPIS, Renata P. Lima. O Professor de Filosofia: o ensino de Filosofia no Ensino Médio como experiência filosófica. In: Caderno Cedes, Campinas, vol. 24, n. 64, p. 305-320, set./dez. 2004

CABRERA, Julio. O cinema pensa: uma introdução à filosofia através dos filmes. Rio de Janeiro: Rocco, 2006.

CERLETTI, Alejandro. O Ensino de filosofia como problema filosófico. Belo Horizonte: Autêntica Editora, 2009.

FOUCAULT, Michel. História da sexualidade 3: o cuidado de si. 8 ed. Rio de Janeiro: Graal, 1984. 